\title{
Animal models for the study of trace metal requirements
}

\section{By P. J. Aggett, University of Aberdeen Medical School and N. T. Davies, Rowett Research Institute, Bucksburn, Aberdeen}

In this paper six of the trace elements which are essential for optimum human health will be considered. These are copper, zinc, manganese, molybdenum, chromium and selenium. For each element the realization that it may be essential for man was preceded by the demonstration of a similar dependence either in experimental animals or in livestock inadvertently deprived of the micronutrient. This account will review the value of animal models in identifying possible human requirements for a trace metal and while it is not reliable to extrapolate from such studies to man in determining human quantitative requirements the important contribution which animal studies have made in identifying factors which modify quantitative requirements for these elements will also be outlined.

Early this century the ubiquity of trace amounts of certain metals in biological material stimulated efforts to investigate their possible biological function (Underwood, 1977). Cu was reported to be essential for growth and haemoglobin synthesis in rats in 1928 (Hart et al. 1928) and soon afterwards endemic nutritional $\mathrm{Cu}$ deficiency was recognized in cattle. Hart and his colleagues feeding rats purified diets then succeeded in demonstrating that $\mathrm{Mn}$ and $\mathrm{Zn}$ were essential micronutrients, and subsequently these dependencies have been shown in all species studied (Underwood, 1977). Further investigations using purified diets have enabled the identification of $\mathrm{Mo}, \mathrm{Cr}$ and $\mathrm{Se}$ as essential dietary components in animals. More recently, the use of plastic isolators fitted with filters and airlocks to exclude atmospheric dust (Smith \& Schwarz, 1967) and create 'trace element sterile environments' has provided evidence that tin, nickel, silicon, vanadium, arsenic, lead and cadmium may be essential. None of these elements have been shown to be essential for man.

Extension of experience with animals to man has been slow. The possibility that $\mathrm{Zn}$ deficiency may contribute to the features of human vitamin deficiency states was considered soon after the original studies with $\mathrm{Zn}$ deficient animal studies (Eggleton, 1939) but it was not until the 1960s, in Iran and Egypt, that human $\mathrm{Zn}$ deficiency syndromes were identified (Prasad, 1978). These patients exhibited some features of $\mathrm{Zn}$ deficiency in common with the earlier description in animals. They had growth retardation with delayed skeletal maturation, icthyosis and hypogonadism. An associated anaemia responded to Fe supplements but the other manifestations only resolved after oral $\mathrm{Zn}$ supplements had been given. The more florid features of $\mathrm{Zn}$ deficiency such as parakeratosis, eczematous dermatitis, alopecia, impaired immunity and diarrhoea were not observed in man until it was realized that the features of acrodermatitis enteropathica were those of a profound $0029-665^{1 / 80} / 3933-4105 \$ 01.00 \bigcirc 1980$ The Nutrition Society 
$\mathrm{Zn}$ deficiency state. Oral zinc supplements induce a complete clinical remission in this rare autosomal recessive disease (Moynahan \& Barnes, 1973) and the pathogenesis of this condition has been related to a defect in the intestinal absorption of $\mathrm{Zn}$ (Lombeck et al. 1975; Aggett et al. 1978). An analogous $\mathrm{Zn}$ responsive condition affecting Friesian calves had been described earlier (Brummerstedt et al. 1971). The similarity between the two conditions (Weismann \& Flagstad, 1976) has advanced understanding of the essentiality of $\mathrm{Zn}$, especially in cell mediated immune function, and has stimulated research in other species but the valuable role which the cattle model should have both in investigating the molecular basis of acrodermatitis enteropathica and the study of Zn metabolism in general has not been fully exploited.

The features of $\mathrm{Cu}$ deficiency in animals include growth retardation, diarrhoea, defective pigmentation and hair formation, impaired collagen and elastin formation which results in ligamentous damage and vascular abnormalities, abnormal myelination of nervous tissue leading to neurodegeneration, and skeletal changes which include scorbutic bone changes, osteoporosis and pathological fractures. Only 3 years after an assertion that human Cu deficiency was an unlikely event (Wintrobe, 1961), Cordano et al. (1964) noted that some infants being rehabilitated from malnutrition on modified cow's milk formula feeds developed an Fe resistant anaemia, neutropenia, metaphyseal flaring and periosteal reactions. All these features responded to $\mathrm{Cu}$ supplementation.

Another human $\mathrm{Cu}$ deficiency state became apparent when Danks et al. (1972) noted that the clinical and biochemical features of Menkes' syndrome, an X-linked neurodegenerative condition (Menkes et al. 1962), resembled those of severe $\mathrm{Cu}$ deficiency as encountered in sheep.

Two mouse models with inherited defects of $\mathrm{Cu}$ metabolism are known. In one, the crinkled mouse, the defect is an autosomal recessive trait which can be ameliorated by giving $\mathrm{Cu}$ supplements to the mothers during pregnancy and lactation. The other mutant is the mottled mouse which has an $\mathrm{X}$-linked recessive inheritance and which is similar to Menkes' steely hair syndrome. This similarity has stimulated detailed investigation of the metabolic defect in the animal model (Hunt, 1974; Mann, Camakaris, Danks \& Walliczek, 1979; Mann, Camakaris \& Danks, 1979; Camakaris et al. 1979). Studies of tissue $\mathrm{Cu}$ levels in II-d-old mutant mice and of boys with Menkes' syndrome at autopsy suggest a similar basic defect in both conditions. Comparisons are possibly limited, however, by species differences. The affected human foetus has a raised $\mathrm{Cu}$ content in all organs except the liver but in the mottled mouse foetus all organs except the kidneys have a depressed $\mathrm{Cu}$ content. Unlike the human infant in whom liver $\mathrm{Cu}$ is accumulated in utero the mouse appears to establish hepatic $\mathrm{Cu}$ reserves postnatally and this is reflected in a slight increase in liver $\mathrm{Cu}$ even in the mottled mutant mouse (Prins \& van den Hamer, 1978). Further dissimilarity between the two conditions is exemplified by the increased $\mathrm{Cu}$ content found in the distal small intestine mucosa of the mouse. This is probably due to pinocytotic activity (Mann, Camakaris \& Danks, 1979); an ability which is not apparent to the same degree in 
the human infant. Neurological maturation occurs later in the mouse than in man, consequentially, effective therapeutic measures used in mice postnatally would need to be given to the affected human foetus in utero to achieve the same results (Mann, Camakaris, Danks \& Walliczek, 1979) and the prospects of effective therapy for the human disease remain gloomy. Minor species differences amongst mammals in the manifestations of $\mathrm{Cu}$ deficiency may, therefore, reflect different functional maturation of organs rather than species differences in the fundamental biochemical role of the metal, and studies on patients with Menkes' disease are stimulating further investigation of $\mathrm{Cu}$ deficiency in other species.

The difficulty of identifying animal models for the study of human Se requirements has been implied by the apparent species differences in the manifestations of its deficiency. In non-ruminants hepatic necrosis is a feature of Se deficiency whilst muscular dystrophy occurs in ruminants. Studies in animal models have shown that a reduction of the antioxidant activity of the Se dependent enzyme glutathione peroxidase precedes the clinical manifestations of Se deficiency and that the development of these features are modified by the interaction of factors such as the severity of oxidant stress, the availability of other antioxidants such as vitamin $\mathrm{E}$ and the dietary content of polyunsaturated fatty acids. These factors probably account for species and individual variation in susceptibility to selenium deprivation and one should not be too surprised that myopathic features have been described in human selenium deficiency. One report describes the efficacy of selenium supplements in a woman who developed muscle pains while on intravenous feeding (van $\mathrm{Rij}$ et al. 1979) and another reports a selenium responsive cardiomyopathy in China (Anon, 1979).

Experience derived from the study of $\mathrm{Zn}, \mathrm{Cu}$ and Se requirements indicates that further comparative studies in other trace element deficiency states might enable the identification of biochemical criteria which would help the determination of human nutritional status and the resolution of human requirements for essential trace elements.

The observation that $\mathrm{Cr}$ augmented the action of insulin in some species including sub-human primates (Mertz, 1974) led to its successful therapeutic trial in maturity onset diabetes mellitus. There have been conflicting reports of abnormal Cr metabolism in both juvenile and adult onset diabetes, but abnormal glucose tolerance associated with a neuropathy was a prominent feature in two case reports of $\mathrm{Cr}$ deficiency occurring in patients on intravenous feeding (Jeejeebhoy et al. 1977; Freund et al. 1979). These findings indicate a need to elucidate human $\mathrm{Cr}$ metabolism and requirements.

The only description of human Mn deficiency was in a volunteer who was on a vitamin $\mathrm{K}$ deficient semi-synthetic diet from which $\mathrm{Mn}$ had been accidentally excluded. He developed hypercholesterolaemia and a prolonged prothrombin time which only improved after Mn supplementation (Doisey, 1974). Studies in Mn deficient animal models indicate the element's important role in carbohydrate, lipid and glycoprotein metabolism (Leach \& Lilburn, 1978) and preliminary evidence of malabsorption in children with exocrine pancreatic insufficiency (Aggett $e t$ al. 
1979) indicate the importance of studying human $\mathrm{Mn}$ requirements in clinical medicine in the context of these functions.

Human Mo deficiency is even less well documented but it has been proposed that an abnormality of Mo metabolism was the cause of a combined defect of xanthine oxidase and sulphite oxidase activity described in a child (Duran et al. 1979) whose features resembled those seen in rats with Mo deficiency induced by the administration of tungsten (Johnson et al. 1974).

\section{Determination of quantitative requirements of trace elements in man and animals}

There are two major approaches used to investigate trace element requirements in animals. One method is to feed a diet frankly deficient in a specific element and to determine the amount of supplementation needed either to prevent the pathological features of deficiency or to achieve 'optimum health' at which neither biological processes nor the utilization of other essential nutrients are impaired.

The second method is the factorial approach or metabolic balance technique. This involves analysis of the micronutrient content of the oral intake, faeces and urine, thereby allowing assessment of a net intestinal absorption and of maximal retention. Analysis of sweat, desquamated skin, shed hair and menstrual loss improves the precision of estimates of retention. Balance studies conducted at different dietary intakes of the element permits the use of regression analysis to determine the minimal intake required to achieve zero net balance. Animal nutritionists have refined factorial analysis to allow for the net requirement of elements for maintenance purposes $(\mathrm{Rm})$, for production during growth, pregnancy and lactation (Rp) and to account for the tissue storage of the element and for obligatory losses in faeces and urine (E). The net requirement $(R n)$ is the summation of these factors:

$$
\mathbf{R n}=\mathbf{R} \mathbf{p}+\mathbf{R m}+\mathrm{E} \text {. }
$$

The total dietary requirement $(\mathrm{Rd})$ is calculated from the equation:

$$
\mathbf{R d}=\frac{\mathrm{Rn}}{\mathrm{A}} \text {, }
$$

where A (availability) represents the proportion of the element in the diet which is absorbed. In animal models the validity of balance techniques and of factorial analysis can be confirmed by carcass analysis of growing animals and by analysis of foetuses, placentas and amniotic fluid during pregnancy and of milk during lactation.

Of the two methods outlined above the balance technique is the most applicable to human studies. It is clearly not possible to apply the determinations involved in a comprehensive factorial analysis to man but valuable information about trace element accumulation could be derived from studies of abortions, stillbirths and accident victims. Such analyses have facilitated estimates of the trace metal requirements for foetal growth and storage (Widdowson et al. 1974) and set the criteria for adequate nutrition in the neonate. The value of the balance technique can be improved by procedures designed to measure true absorption and 
endogenous faecal loss of essential trace elements. Use of extrinsic or intrinsic radioisotope labels in the diet allows true absorption and endogenous losses to be calculated if the apparent absorption is also known. Alternatively, endogenous loss has been assessed by giving a radioisotope intravenously and estimating the ratio of labelled and non-labelled elements in the body's 'metabolically active pool'. The contribution of the endogenous element to the faecal loss can then be determined by measuring the specific activity of the isotope in faeces. Weigand \& Kirchgessner (1976) have applied this technique to studies of animal $\mathrm{Zn}$ homoeostasis and absorption using measurements of ${ }^{65} \mathrm{Zn}$ in tissues and urine as an indicator of its distribution in the metabolic pool.

Isotopic techniques for measuring trace element availability and endogenous loss from diets has been used in man but ethical considerations preclude the use of radioisotopes during pregnancy and lactation or on young infants and adolescents. However, such considerations would not apply to the use of stable isotopes as markers and this approach has recently been reported for the assessment of absorption of $\mathrm{Zn}$ and $\mathrm{Cu}$ in human volunteers (King et al. 1978).

Suttle (1974) has adopted an non-isotopic repletion technique to determine endogenous losses and availability of $\mathrm{Cu}$ in ewes. Essentially they compared the period of protection afforded to $\mathrm{Cu}$ deficient animals by a single injection of intravenous $\mathrm{Cu}$ with that afforded by a dietary supply. They have since extended this technique to studies in calves (Suttle, 1978). However, both the efficiency of the absorptive process and hence the availability and the rate of endogenous loss of an element may vary with the animals' nutritional status for that element. The results obtained, therefore, in such studies may not be applicable in normal equilibrium. This intravenous repletion technique has been assessed in studies of $\mathrm{Cu}$ requirements of two patients on intravenous feeding (Dunlap et al. 1974) in whom the efficacy of single doses of copper sulphate in preventing the appearance of $\mathrm{Cu}$ deficiency symptoms was assessed. Recently, Wolman et al. (1979) have combined balance and intravenous repletion techniques on intravenously fed patients to determine minimal $\mathrm{Zn}$ requirements. All these studies relate to disease states, however, and cannot be assumed to be representative of requirements in health.

All species are especially susceptible to trace element deficiencies during anabolic phases such as growth and reproduction. Animal studies confirm that trace element absorption is increased during these phases as is that of the major nutrients. Absorption of trace elements is also modified by the existing nutritional status of the animal and by pathological states such as infections (Underwood, 1977). These adaptive responses have yet to be confirmed in man but are clearly pertinent to the selection of models.

Interactions with other organic and inorganic dietary components alter the efficiency with which a specific trace element is absorbed (Davies, 1979). In order to avoid being misled by such interactions when assessing requirements one should also know the complete dietary composition. A diet with high calcium content, for example, is associated with an increased $\mathrm{Zn}$ retention but because the $\mathrm{Zn}$ is 
diverted from its normal maintenance and protective roles the risk of marginal $\mathrm{Zn}$ nutritional status is increased (Kirchgessner et al. 1960) and this interaction has been used to precipitate $\mathrm{Zn}$ deficiency in an adolescent girl with suspected acrodermatitis enteropathica (Portnoy \& Molokhia, 1974). Animal studies indicate that excessive dietary concentrations of one element may influence the absorption of another essential trace element. Some of these reactions such as the adverse effect of sulphur and Mo on $\mathrm{Cu}$ absorption are of importance mainly to ruminants (Underwood, 1977). The observation, however, that high $\mathrm{Cu}$ intakes in pigs can induce $\mathrm{Zn}$ deficiency (Suttle \& Mills, 1966 ) and that the converse occurs in other species (Hill \& Matrone, 1968 ) is relevant to the observations that prolonged $\mathrm{Zn}$ therapy in humans can induce $\mathrm{Cu}$ deficiency (Prasad et al. 1978).

The beneficial effects of human milk in acrodermatitis enteropathica compared with the deterioration which is induced by cow's milk has stimulated interest in the bioavailability of $\mathrm{Zn}$, and other trace metals from milks and in the possible presence of species specific ligands which may mediate intestinal absorption of trace metals (Duncan \& Hurley, r 978; Lonnerdal et al. 1980). The increased use of semi-synthetic dietary preparations in therapeutic and domestic diets has increased the importance of knowing the bioavailability of trace metal content and this constitutes a major problem in determining human trace metal requirements.

Increased dietary requirements for $\mathrm{Zn}$ and possibly $\mathrm{Mn}$ and $\mathrm{Cu}$ in phytate rich diets have been emphasized by numerous animal studies (reviewed by Davies, 1978). Phytate is present in all cereals and many legumes and can form stable metal complexes within the intestinal lumen and hence reduce bioavailability. The importance of this interaction was noted by Reinhold et al. (1973) in their nutritional studies on human zinc deficiency. Recently, Davies \& Olpin (1979) have shown that molar phytate:zinc values in excess of 15 caused features of $\mathrm{Zn}$ deficiency in rats even if the $Z n$ intake was greatly increased above normal. Further studies by Reinhold and his colleagues indicate that under some circumstances binding of $\mathrm{Zn}, \mathrm{Cu}$ and $\mathrm{Fe}$ to fibre constituents may be of equal or greater importance than phytate in limiting their absorption (Reinhold et al. 1976). However, results from animal studies have failed to substantiate these effects (Davies et al. 1976).

From the foregoing discussion it is evident that knowledge of trace metal metabolism is, at best, fragmentary and that this is limiting the selection of appropriate animal models for studies related to human trace metal requirements. The choice of model is also limited in some instances by inadequate information about the maturational characteristics and other metabolic functions in various species and how these compare with man. Nevertheless, there is a need to use animal models to identify criteria which could be used epidemiologically to assess human trace metal status, and to develop models whereby the bioavailability of the trace metal content of novel and natural foodstuffs can be assessed. To meet these requirements further comparative studies of trace metal metabolism in various species is necessary to elucidate the fundamental role of a particular trace metal. It is already apparent from animal studies that previously accepted criteria of 
nutritional status such as plasma $\mathrm{Zn}$ and $\mathrm{Cu}$ concentrations, or anaemia in $\mathrm{Cu}$ deprivation are unreliable and late indicators of deficiency. Biochemical changes such as depressed metalloenzyme activity precede these events and, in our experience, subtle psychological changes may even precede some of those biochemical changes which are currently determined as indicators of $\mathrm{Zn}$ and $\mathrm{Cu}$ deficiency. This is a rewarding area for further research and is pertinent both to the determination of human trace metal requirements and the ultimate validation in man of specific recommendations, derived from studies on animals, on the trace metal composition of human foodstuffs.

P.J.A. thanks the Rank Prize Fund for financial support.

\section{REFERENCES}

Aggett, P. J., Atherton, D. J., Delves, H. T., Thorn, J. M., Bangham, A., Clayton, B. E. \& Harries, J. T. (1978). Trace element metabolism in man and animals, p. 418 [M. Kirchgessner, editor]. Freising-Weihenstephan, Germany: Arbeitskreis für Tierernahrungsforschung Weihenstephan.

Aggett, P. J., Thorn, J. M., Delves, H. T., Harries, J. T. \& Clayton, B. E. (1979). Monogr. Paediat. ro, 8.

Anon, (1979). Lancet, i, 889 .

Brummerstedt, E., Flagstad, T., Basse, A. \& Anderson, E. (197r). Acta Path Microbio. Scand, $79,686$.

Camakaris, J., Mann, J. R. \& Danks, D. M. (1979). Biochem. F. 180, 597.

Cordano, A., Baertl, J. M. \& Graham, G. G. (1964). Pediatrics, Springfield, 34, 324.

Danks, D. M., Campbell, P. E., Walker-Smith, J., Stevens, B. J., Gillespie, J. M., Blomfield, J. \& Turner, B. (1972). Lancet, i, i 100.

Davies, N. T. (1979). Proc. Nutr. Soc. 38, 121.

Davies, N. T., Hristic, V. \& Flett, A. A. (1976). Nutr. Rep. Int. I5, 207.

Davies, N. T. \& Olpin, S. E. (1979). Br. F. Nutr. 41, 590.

Doisey, E. A. (1974). Trace element metabolism in animals, vol. 2, p. 664 [W. G. Hoekstra, editor]. Baltimore: University Park Press.

Duncan, J. R. \& Hurley, L. S. (1978). Am. F. Physiol. 235, 556.

Dunlap, W. M., James, G. W. \& Hume, D. M. (1974). Ann. intern. Med. 80, 470.

Duran, M., Korteland, J., Beemer, F. A., Heiden, C. v.d., de Bree, P. K., Brink, M., Wadman, S. K. \& Lombeck, I. (1979). Models for the study of inborn errors of metabolism, p. 103 [F. A. Hommes, editor]. Amsterdam, Oxford: Elsevier/North-Holland Biomedical Press.

Eggleton, W. G. E. (1939). Biochem. F. 33, 403.

Freund, H., Atamian, S. \& Fischer, J. E. (1979). F. Am. Med. Ass. 241, 496.

Hart, E. B., Steenbock, H., Waddell, J. \& Elvehjem, C. A. (1928). f. biol. Chem. 77, 797.

Hill, C. H. \& Matrone, G. (1968). Fedn Proc. Fedn Am. Socs exp. Biol. 19, 1474.

Hunt, D. M. (1974). Nature, Lond. 249, 852.

Jeejeebhoy, K. N., Chu, R. C., Marliss, E. B., Greenberg, G. R. \& Bruce-Robertson, A. (1977). Am. F. clin. Nutr. 30, $53 \mathrm{I}$.

Johnson, J. L., Cohen, H. J. \& Rajagopalan, K. U. (1974). F. biol. Chem. 249, 5046.

King, J. C., Raynolds, W. L. \& Margen, S. (1978). Am. F. clin. Nutr. 31, i 198.

Kirchgessner, K. M., Munz, W. \& Oelschlager, W. (1960). Arch. Tierernähr 10, 1.

Leach, R. M. \&c Lilburn, M. S. (1978). Wld Rev. Nutr. Diet. 32, 123.

Lombeck, I., Schnippering, H. G., Ritzl, F., Feinendegen, L. E. \& Bremer, H. J. (1975). Lancet i, 855 .

Lonnerdal, B., Stanislowski, A. G. \& Hurley, L. S. (1980). F. inorg. Biochem. 12, 71.

Mann, J. R., Camakaris, J. \& Danks, D. M. (1979). Biochem. F. 180, 61 3. 
Mann, J. R., Camakaris, J., Danks, D. M. \& Walliczek, E. G. (1979). Biochem. F. 180, 605.

Menkes, J. H., Alter, M., Steigleder, G. K., Weakley, D. R. \& Sung, J. H. (1962). Pediatrics, Springfield, 29, 764 .

Mertz, W. (1974). Proc. Nutr. Soc. 33, 307.

Moynahan, E. J. \& Barnes, P. M. (1973). Lancet i, 676.

Portnoy, B. \& Molokhia, M. (1974). Br. F. Dermatol. 91, 701.

Prasad, A. S. (1978). Trace elements and iron in human metabolism. New York, Chichester: John Wiley \& Sons.

Prasad, A. S., Brewer, G. J., Schoomaker, E. B. \& Rabbani, P. (1978). F. Am. Med. Ass. 240, 2166.

Prins, H. W. \& van den Hamer (1978). Trace element metabolism in man and animals, 3 [M. Kirchgessner, editor]. Freising-Weihenstephan, Germany: Arbeitskreis für Tierernahrungsforschung Weihenstephan.

Reinhold, J. G., Faradji, B., Abadi, P. \& Ismail-Beige, F. (1976). Trace elements in human health and disease, vol. I [A. S. Prasad, editor]. New York: Academic Press.

Reinhold, J. G., Nasr, K., Lahimgarzaden, A. \& Hedayati, H. (1973). Lancet i, 283.

Smith, J. C. \& Schwarz, K. (1967). J. Nutr. 93, 182.

Suttle, N. F. (1974). Br. F. Nutr. 32, 295.

Suttle, N. F. (1978). Trace element metabolism in man and animals, 3, p. 473 [M. Kirchgessner, editor]. Freising-Weihenstephan, Germany: Arbeitskreis für Tierernahrungsforschung Weihenstephan.

Suttle, N. F. \& Mills, C. F. (1966). Br. F. Nutr. 20, 135.

Underwood, E. J. (1977). Trace elements in human and animal nutrition, $4^{\text {th }}$ ed. New York: Academic Press.

van Rij, A. M., Thomson, C. D., McKenzie, J. M. \& Robinson, M. F. (1979). Am. F. clin. Nutr. 32, 2076.

Weigand, E. \& Kirchgessner, M. (1976). Nutr. Metabol. $20,307$.

Weismann, K. \& Flagstad, T. (1976). Acta. Dermatovener 56, 151.

Widdowson, E. M., Dauncey, J. \& Shaw, J. C. (1974). Proc. Nutr. Soc. 33, 275.

Wintrobe, M. M. (1961). Clinical Haematology, 5th ed. p. I4I [Lea \& Febiger, editors]. Philadelphia.

Wolman, S. L., Anderson, G. H., Marliss, E. B. \& Jeejeebhoy, K. N. (1979). Gastroenterology, $76,45^{8}$. 